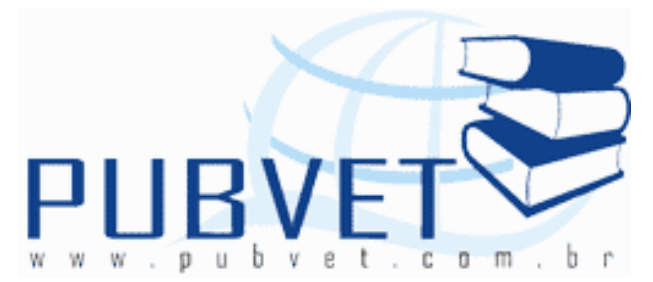

PUBVET, Publicações em Medicina Veterinária e Zootecnia.

\title{
Qualidade da carne bovina: \\ processo de abate e contaminação causada por Escherichia coli
}

\author{
Fernanda Ferreira Pessoa ${ }^{1}$ e Keila Maria Roncato Duarte²
}

1 Mestranda do Curso de Produção Animal Sustentável, Instituto de Zootecnia . Rua Heitor Penteado, 56 Nova Odessa, SP 13460-000, e-mail : nandapessoa83@yahoo.com.br

2 Pesquisadora Cientifica. CPDNAP Instituto de Zootecnia. Rua Heitor Penteado 56, Nova Odessa, SP 13460-000. e-mail: keila@iz.sp.gov.br

\section{Resumo}

Os surtos de enfermidades transmissíveis causadas por alimentos, nesse caso a carne, é alvo de preocupação para as indústrias alimentícias e para os órgãos de Saúde Pública. O objetivo desse trabalho é mostrar que hoje a alimentação, influencia decisivamente à saúde dos indivíduos e da população, desempenhando um papel crucial na manutenção e na prevenção de diversas doenças, assim como a existência da bactéria Escherichia Coli nos alimentos, carregando enfermidades transmissíveis ao homem, e reduzindo a confiança dos consumidores em relação à saúde. Hoje um produto de qualidade é aquele que atende perfeitamente de forma confiável, acessível, segura, e higiênica no tempo certo, às necessidades do cliente. É preciso esclarecer que o risco da carne se contaminar é grande e certos cuidados devem ser tomados desde a criação até a comercialização do produto.

Palavras-chave: carne bovina, processos de abate, Escherichia coli 
PESSOA, F.F. e DUARTE, K.M.R. Qualidade da carne bovina: processo de abate e contaminação causada por Escherichia coli. PUBVET, Londrina, V. 5, N. 37, Ed. 184, Art. 1238, 2011.

\title{
Beef quality: slaughtering process and Escherichia coli contamination
}

\begin{abstract}
Outbreaks of disseminated diseases caused by food contamination, in this case, meat it is a great concern for the food industry and the organs of Public Health. The aim of this work was to show that today's food, significantly influences the health of individuals and the population, playing a crucial role in the maintenance and prevention of several diseases, as well as the existence of the bacterium Escherichia coli in food, carrying diseases transmissible to humans and reducing consumer confidence in relation to health. Today a quality product is one that fits perfectly in a reliable, affordable, safe, hygienic and on time, customer needs. We must clearly that the risk of meat infection is great and some precautions should be taken from farm raising to product marketing.
\end{abstract}

Keywords: beef, slaughter processes, Escherichia coli

\section{INTRODUÇÃO}

A carne é um dos alimentos mais nutritivos utilizados na alimentação humana. É uma fonte rica em proteínas de alta qualidade, ferro e vitamina B (Aberle et al., 2001), sendo classificada como um alimento completo e de alto valor biológico, por apresentar todos os aminoácidos essenciais nas proporções corretas.(Pensel, 1998 citado por Marques et. al.,2006).

Os alimentos cárneos particularmente aqueles que passam por apreciável manuseio, se constituem em excelente meio de cultura devido à elevada porcentagem de umidade, ph próximo a neutralidade e composição rica em nutrientes, favorecendo a instalação, sobrevivência e multiplicação de grande número de microrganismos capazes de provocar toxinfecções no homem (FRAZIER, WESTHOFF, 1993).

As características físico-químicas $(\mathrm{pH}$, final, cor, maciez, e capacidade de retenção de água ) da carne determinam sua qualidade e aceitabilidade, sendo 
PESSOA, F.F. e DUARTE, K.M.R. Qualidade da carne bovina: processo de abate e contaminação causada por Escherichia coli. PUBVET, Londrina, V. 5, N. 37, Ed. 184, Art. 1238, 2011.

importante tanto para os varejistas como para os consumidores. (Rota et al., 2006)

Por esse motivo sempre avaliamos o $\mathrm{pH}$ da carne, esse dado funciona como indicador da qualidade da carne. A variação do $\mathrm{pH}$ influencia diretamente no prazo de validade de nossos produtos e pode indicar variações na maciez, coloração e até na possibilidade de sobrevivência de vírus e bactérias presentes na carne.

Avaliando $100 \%$ das meias carcaças permitindo a classificação das mesmas, o $\mathrm{pH}$ deve ser avaliado entre a $12^{\circ}$ e a $13^{\circ}$ vértebra evitando que a ponteira encoste na gordura; já para o aproveitamento das meias carcaças para produção de resfriados, o pH deve estar entre 5,4 e 5,97.

A carne é um alimento protéico de alta qualidade não só por conter aminoácidos essenciais, mas também pela proteína ser altamente digestível e facilmente absorvível (Aberle et al.,2001)

Além da importância na alimentação a carne também representa para o Brasil uma fonte de rendas e grande valor econômico. O Brasil possui o maior rebanho do mundo, superando inclusive o número de habitantes no país (IBGE 2007).

A qualidade da carne que chegará para o consumidor recebe grande influencia que vai desde o manejo do animal na propriedade rural até o momento do abate, sendo necessário que o abate ocorra sem sofrimento para o animal, e diminuindo assim a carga de estresse, obtendo uma carne mais macia. (UFES,2007)

Quando se fala de abate de bovinos alguns cuidados devem ser tomados, pois existem etapas nesse processo que são consideradas críticas para a contaminação de carcaças por microrganismos. Para a realização de um bom abate, os animais não devem ser estressados desnecessariamente, a sangria deve ser eficiente, evitando as contusões das carcaças e seguindo todas as normas do RIISPOA (Regulamento de Inspeção Industrial e Sanitária dos Produtos de Origem Animal) devem ser seguidas. $O$ abate tem que ser higiênico e seguro aos operadores. (UFES, 2007) 
PESSOA, F.F. e DUARTE, K.M.R. Qualidade da carne bovina: processo de abate e contaminação causada por Escherichia coli. PUBVET, Londrina, V. 5, N. 37, Ed. 184, Art. 1238, 2011.

São seguidas também as normas das Boas Práticas de Fabricação, que abrangem um conjunto de medidas que devem ser adotado pelas indústrias de alimentos a fim de garantir a qualidade sanitária e a conformidade dos produtos alimentícios com os regulamentos técnicos. A legislação sanitária federal regulamenta essas medidas em caráter geral, aplicável a todo tipo de indústria de alimentos, e específico, voltadas às indústrias que processam determinadas categorias de alimentos. ( CNPC, 2011 )

Processos de abate - Matadouros ou frigoríficos são estabelecimentos dotados de instalações completas e equipamentos adequados para o abate, manipulação, preparo e conservação da carne.

As instalações completas para o abate envolvem: currais de chegada e seleção, curral de observação e departamento de necropsia, rampa de acesso à matança, com chuveiros e seringa, área de atordoamento, boxe do atordoamento e área de vômito, sala de matança com subseções (sangria, esfola, evisceração, toalete, seções de miúdos,) instalações frigoríficas e graxaria.

Com relação à higiene e boas práticas industriais o abate incluem todas as medidas que objetiva a produção de carne com o mínimo possível de contaminação, propondo as seguintes medidas:

- medidas higiênicas durante o transporte,

- inspeção ante-mortem e separação dos animais sãos e doentes,

- divisão do processo de abate para minimizar a contaminação cruzada, ou seja, divisão e linha de abate em três partes distintas:

1-) Currais e área de atordoamento

2-) Área de sangria e esfola- parte suja,

3-) Evisceração, inspeção e preparo da carcaça para o resfriamento, parte limpa,

- resfriamento adequado, e manutenção da cadeia de frio durante a desosssa, corte e transporte, 
PESSOA, F.F. e DUARTE, K.M.R. Qualidade da carne bovina: processo de abate e contaminação causada por Escherichia coli. PUBVET, Londrina, V. 5, N. 37, Ed. 184, Art. 1238, 2011.

- limpeza, saneamento eficiente controlado por exames bacterianos,

- treinamento e instrução do pessoal,

- controle eficiente da higiene durante o processo de abate. ( ROÇA, 1993 )

Transporte de animais - $\mathrm{O}$ transporte é feito por caminhões boiadeiros. A capacidade de carga média é de 5 animais na parte anterior e posterior e 10 animais na parte intermediária, totalizando 20 bovinos.

O transporte em condições desfavoráveis, conduzem a lesões, contusões, perda de peso e estresse dos animais.( UFES,2007 )

Descanso e dieta hídrica- Para que ocorra a recuperação dos animais devido ao transporte, eles necessitam passar por um período de descanso que melhore a qualidade da carne, pois os níveis de adrenalina e de glicose presentes no sangue voltam ao normal. O jejum reduz o conteúdo gástrico para facilitar a evisceração do animal. Os animais devem permanecer em descanso, jejum e dieta hídrica nos currais por 24 horas e esse tempo poderá ser reduzido em função da distância percorrida pelo animal até o abatedouro. (RIISPOA).

Durante esse tempo que os animais permanecem em descanso e dieta hídrica, é realizada a inspeção ante-mortem, com as seguintes finalidades:

- exigir e verificar os certificados de vacinação de sanidade do gado;

- identificar o estado higiênico sanitário dos animais para auxiliar, informações dos danos causados, a tarefa de inspeção pós-mortem

- identificar e isolar os animais doentes ou suspeitos, antes do abate, bem como vacas com gestação adiantada e recém paridas, -verificar as condições higiênicas dos currais e anexos. (DIPOA)

Banho de Aspersão ou lavagem dos animais - Após o período de descanso, os animais são conduzidos por uma rampa ao boxe de atordoamento e nessa rampa é feito a lavagem dos animais, por um banho de aspersão. No final da rampa existe um afunilamento, conhecido como seringa, permitindo a 
PESSOA, F.F. e DUARTE, K.M.R. Qualidade da carne bovina: processo de abate e contaminação causada por Escherichia coli. PUBVET, Londrina, V. 5, N. 37, Ed. 184, Art. 1238, 2011.

passagem de um animal por vez. Segundo o Ministério os chuveiros podem ser direcionados de cima para baixo, para as laterais dos animais, e de baixo para cima. O que permite uma lavagem melhor do esterco e de outras sujidades antes do abate.

Essa lavagem é realizada antes do abate para limpar a pele do animal, tendo assim uma esfola higiênica. A limpeza dos cascos, região do ânus e extremidades devem ser feitas no curral com mangueiras. Os animais devem permanecer um tempo na rampa para que a pele seque e a esfola seja realizada corretamente.

Atordoamento ou insensibilização - $O$ atordoamento ou a insensibilização, pode ser considerada a primeira operação do abate propriamente dito. Determinado pelo processo adequado, o atordoamento, consiste em colocar o animal em um estado de inconsciência, que perdure até o fim da sangria, não causando sofrimento desnecessário e promovendo uma sangria tão completa quando possível. A concussão cerebral, que é o método utilizado no Brasil, é realizado através da marreta, martelo pneumático, ou pistola pneumática. A lesão encefálica ou injúria cerebral difusa provocada pela pancada súbita e pelas alterações da pressão intracraniana, resultando na deformação rotacional do cérebro, promove incoordenação motora, porém mantém atividade cardíaca e respiratória. ( $B A R G E R$, F. et al; 1990).

A degola ou jugulação cruenta, segue habitualmente os rituais judaicos, e consiste em um corte transversal do pescoço, por meio de uma incisão rápida com a faca, que corta a pele, os músculos, o esôfago, a traquéia, as artérias carótidas e as veias jugulares. Alega-se que o método judaico de abate não implica em nenhum ato de crueldade porque a faca é afiada, porque o corte das carótidas é seguido de uma queda brusca de pressão sanguínea das artérias cerebrais, ocorrendo assim uma anóxia cerebral que produz inconsciência quase instantânea, portanto, logo após a incisão, pode ocorrer persistência do reflexo ocular e convulsões, comprovando que a inconscientização não é imediata, pois a perda da sensibilidade ocorre 10 
PESSOA, F.F. e DUARTE, K.M.R. Qualidade da carne bovina: processo de abate e contaminação causada por Escherichia coli. PUBVET, Londrina, V. 5, N. 37, Ed. 184, Art. 1238, 2011.

minutos após a degola. Após a insensibilização o animal desliza sobre a grade tubular da área de vômito e é suspenso ao trilho aéreo por um membro posterior, com o auxílio de um gancho e uma roldana. Neste momento, geralmente ocorre regurgitação, devendo o local ter água em abundância para lavagem.

Sangria - A sangria é realizada pela abertura sagital da barbela através da linha alba e seç̧ão da aorta anterior e veia cava anterior, no início das artérias carótidas e final das veias jugulares. O sangue é então recolhido pela canaleta de sangria. É conveniente a utilização de duas facas de sangria: uma para incisão da barbela e outra para o corte dos vasos. As facas devem ser mergulhadas na caixa de esterilização após a sangria de cada animal, tendo em vista que os microrganismos da faca já foram encontrados nos músculos e na medula óssea. ( Ministério da Agricultura )

Vários fatores são responsáveis pela eficiência da sangria, tendo o estado físico do animal antes do abate, método de atordoamento e o intervalo entre o atordoamento e a sangria. Todas as enfermidades que debilitam o sistema circulatório afetam a sangria. As enfermidades febris, agudas, provocam vasodilatação generalizada o que impede uma sangria eficiente. Um problema relacionado com a sangria é o aparecimento de hemorragias musculares caracterizadas por petéquias, listras, equimoses em várias partes da musculatura, provocada por aumento da pressão sanguínea a ruptura capilar. Vários fatores são responsáveis por estas alterações, como o aumento do intervalo entre o atordoamento e a sangria, o estado de tensão dos animais no momento do abate, traumatismos, infecções e ingestão de substâncias tóxicas. ( ROÇA, R.O).

Esfola, remoção do couro e cabeça - A esfola constitui na remoção por separação do panículo subcutâneo. A operação da esfola pode ser dividida nas seguintes fases: ablação dos chifres e das patas dianteiras, abertura da barbela até o omento, incisão longitudinal da pele do peito até o ânus, e corte 
PESSOA, F.F. e DUARTE, K.M.R. Qualidade da carne bovina: processo de abate e contaminação causada por Escherichia coli. PUBVET, Londrina, V. 5, N. 37, Ed. 184, Art. 1238, 2011.

das patas traseiras. Amarra-se para evitar contaminação da carcaça , o ânus e a bexiga.

Nesta fase inicia-se a retirada do couro e a desarticulação da cabeça.

Uma atenção especial deve ser dada a esta fase para evitar contaminação cruzada entre o couro e carne por mãos e facas. Após a separação da pele nas extremidades, às vezes a esfola é completada mecanicamente por tração. A seguir é realizada a oclusão do esôfago e a separação do conjunto cabeça e língua. (ROÇA, R.O)

Evisceração - As carcaças são abertas com serra elétrica ou manualmente. As vísceras são retiradas e carregadas em uma bandeja para inspeção. Após lavagem utilizando água quente, as carcaças são encaminhadas a câmeras frigoríficas ou a desossa, ou seja, as carcaças são divididas em seções menores e cortes individuais para comercialização. (ROÇA, R.O )

Lavagem das carcaças e refrigeração - As carcaças após divididas através de serra elétrica em duas meias carcaças e submetidas à toalete para remoção dos rins, rabo, gorduras e medula, são lavadas através de jatos de água à temperatura de 38 a $40{ }^{\circ} \mathrm{C}$, sob pressão mínima de 3 atmosferas com o objetivo de eliminar esquírolas ósseas, coágulos e pêlos. A efetividade desta operação depende do tempo gasto na lavagem, volume, pressão e a temperatura da água. A lavagem da carcaça com água quente e clorada tem como objetivo reduzir a contagem microbiana da carne fresca. A contaminação bacteriana inicial e a temperatura de armazenamento são os principais fatores que determinam a durabilidade da carne. (SERRANO, A. M)

As meias carcaças são resfriadas para diminuir o crescimento microbiano (conservação). Para reduzir a temperatura interna para menos de $7^{\circ} \mathrm{C}$, elas são resfriadas em câmeras frias com temperaturas entre 0 e $4^{\circ} \mathrm{C}$. 0 tempo normal deste resfriamento para carcaças bovinas, fica entre 24 e 48 horas. (PACHECO E YAMANAKA). 
PESSOA, F.F. e DUARTE, K.M.R. Qualidade da carne bovina: processo de abate e contaminação causada por Escherichia coli. PUBVET, Londrina, V. 5, N. 37, Ed. 184, Art. 1238, 2011.

Com base, na qualidade da carne e os processos de abate, é evidente que existe uma grande preocupação mundial com a contaminação da carne e seus derivados. Devido à sua complexa composição a carne propicia o desenvolvimento de ampla gama de microrganismos, tanto benéficos quanto patogênicos. Os microrganismos que contaminam os produtos cárneos são amplamente distribuídos na natureza, podendo ser encontrado em uma diversidade de ambientes (JAY, 2005).

As bactérias que utilizam as proteínas da carne em seu metabolismo podem causar o aparecimento de odores desagradáveis na carne, podem levar a putrefação, e também estabelecer mudanças na coloração da carne. Já as bactérias que utilizam os lipídeos podem hidrolisar os ácido graxos e rancificar a gordura da carne. Além de produzir alterações nos padrões da carne (odor, sabor e cor), os microrganismos podem causar intoxicações alimentares e uma série de outras doenças que pode colocar em risco à saúde de muitas pessoas. Entre os microorganismos causadores de tóxico-infecções alimentares ou tipo de doenças relacionadas ao consumo de produtos de origem animal destacamse a bactéria Escherichia coli.

Escherichia coli- É a espécie predominante entre os diversos microrganismos facultativos que fazem parte da microbiota intestinal de animal de sangue quente. O significado da sua presença nos alimentos deve ser analisado de dois ângulos: indica contaminação microbiana de origem fecal, portanto condições higiênicas insatisfatórias; e o outro aspecto a ser considerado é que diversas linhagens são comprovadamente patogênicas para o Homem e os animais. A enumeração laboratorial de $E$. coli auxilia na detecção do perigo potencial de uma toxinfecção alimentar através da água e dos alimentos fornecidos ao consumo.(HOBBS; ROBERTS, 1992; FRANCO; LANDGRAF,1996). Entre as amostras patogênicas são determinados, de acordo com seus mecanismos de virulência, seis diferentes grupos de $E$. coli capazes de ocasionarem diarréia.(NATARO, J.P 1998, TRABULSI, L.R 1999 ) 
PESSOA, F.F. e DUARTE, K.M.R. Qualidade da carne bovina: processo de abate e contaminação causada por Escherichia coli. PUBVET, Londrina, V. 5, N. 37, Ed. 184, Art. 1238, 2011.

Os surtos decorrentes da infecção por Escherichia coli (EPEC, EIEC, EaggEC e EHEC) são considerados severos. A Escherichia coli, enterohemorrágica (EHEC) e a E. coli enteroagregativa (EaggEC) destacam-se entre os microrganismos classificados como emergentes. (MARTINS; et. al 2003).

Os sorotipos de (EHEC) são os que produzem duas toxinas responsáveis pela colite hemorrágica no homem, tendo como complicação mais importante a síndrome hemolítica urêmica. O sorotipo O157:H7 é a EHEC mais frequentemente encontrada. A EaggEc foi descrita mais recentemente e está associada a casos crônicos de diarréia.

A E. coli O157: H7 tem sido reconhecida mundialmente nos últimos anos como um dos microrganismos mais envolvidos nos surtos de doenças veiculadas por alimentos em humanos. $O$ reconhecimento das EHEC como uma classe distinta de $E$.coli patogênica resultou de duas observações epidemiológicas ocorridas em 1983. A primeira originou-se a partir da infecção de dois surtos de uma doença gastrintestinal caracterizada por dor abdominal severa, diarréia liquida inicialmente e depois sanguinolenta com nenhuma ou pouca febre.(RYLEY, REMIS .R.S,1983).

Essa colite denominada de hemorrágica foi associada à ingestão de hambúrgueres mal cozidos em um restaurante fast-food. Da amostra de fezes desses pacientes isolou a bactéria E. coli O157:H7. A segunda observação deu conta da associação de casos esporádicos da síndrome hemolítica urêmica (SHU) com a presença de citotoxinas produzidas por E. coli O157:H7 nas amostras de fezes dos pacientes.(KARMALI MA 1983).

A Listeria spp, Escherichia coli enterohemorrágica (EHEC) e a E. coli enteroagregativa (EaggEC) são patógenos emergentes que vem sendo relacionados a diversos surtos de doenças de origem alimentar principalmente por estarem presentes no trato gastrintestinal dos animais, sendo muito comum a contaminação da carcaça e cortes de carne durante o abate ou processamento inadequado. 
PESSOA, F.F. e DUARTE, K.M.R. Qualidade da carne bovina: processo de abate e contaminação causada por Escherichia coli. PUBVET, Londrina, V. 5, N. 37, Ed. 184, Art. 1238, 2011.

Alguns trabalhos científicos, tem demonstrado que fatores como a temperatura, $\mathrm{pH}$, atividade de água, tipo de alimento interferem com a sobrevivência e manutenção da O157:H7 no alimento.

Os relatos citados como o que ocorreu em 1983, contribuem para que o controle microbiológico se apresente como uma etapa essencial durante o processamento da carne, para o fornecimento de um alimento aceitável e seguro ao consumo. Tanto a presença de microrganismos contaminantes quanto a de patógenos podem provocar alterações que descaracterizam o produto ou, no caso de alguns patógenos tornar somente o seu consumo perigoso e impróprio para a saúde humana.

O período de incubação das infecções causadas por $E$. coli é de 3 à 4 dias embora incubações de 5 à 8 dias foram descritas em alguns surtos. A diarréia é um sintoma inicial sendo que algumas vezes é precedida por dores abdominais, vômito e fezes.(TRABULSI LR,1999)

O diagnóstico da $E$. coli é feito geralmente pela pesquisa de bactérias nas fezes do paciente e sua identificação por métodos fenotípicos ou moleculares. (TRABULSI LT,1999).

É de grande preocupação nacional e internacional o potencial risco que $E$. coli pode representar a saúde pública. Este patógeno é um desafio para a indústria alimentícia e para a cadeia alimentar. O risco de ocorrência dos surtos por E. Coli será menor se forem respeitadas as normas de processamento, as boas práticas de higiene, havendo assim a aplicação da análise de perigos e pontos críticos de controle, da contaminação da indústria alimentícia.

\section{Considerações Finais -}

Cabe a indústria determinar a sua necessidade e selecionar os procedimentos de análise de qualidade de carne mais adequados aos seus objetivos. O importante é que a monitoria de qualidade seja empregada como rotina, seleção de animais produtores de carne de melhor qualidade, pagamento diferenciado aos produtores como forma de estimular a produção de animais 
PESSOA, F.F. e DUARTE, K.M.R. Qualidade da carne bovina: processo de abate e contaminação causada por Escherichia coli. PUBVET, Londrina, V. 5, N. 37, Ed. 184, Art. 1238, 2011.

melhores, a identificação de problemas nos processamentos e nos lotes abatidos para posterior gerenciamento dos mesmos, maximização e destino das carcaças, diminuição de perdas, melhoria nas características sensoriais dos produtos, busca pela uniformização das carcaças, cortes e produtos cárneos, e para fins de pesquisas o retorno de informações aos produtores, para que toda cadeia trabalhe em conjunto visando os anseios do consumidor.

Vale lembrar que hoje as características de qualidade são muito valorizadas, como inocuidade e ausência de contaminação microbiológica, ou também por resíduos tóxicos ou produtos químicos, fatores relacionados a segurança alimentar. Além disso, tem grande importância atualmente o bem estar animal e a sustentabilidade da produção, incluindo o controle e as agressões causadas ao meio ambiente.

\section{REFERÊNCIAS BIBLIOGRÁFICAS}

ABERLE, E.D. Forrest, J. C, GERRARD, D. E, MILLS, E.W, Principles of meat science, $4^{\circ}$ ed. Kendall/ Hunt, Iowa, $2001.354 \mathrm{p}$

ABIEC- Associação Brasileira das Indústrias exportadoras de carne.

BAGER, F. SHAW, F.D, TAVENER, A. et al. Comparison of EEG and ECOG for detecting cerebrocortical activity during slaughter calves. Meat Science, Oxon, v. 27, n.3, p.211 - 225, 1990

CETESB - Companhia de Tecnologia de Saneamento Ambiental. T.M.T. Caracterização, reaproveitamento e tratamento de resíduo de frigoríficos, abatedouros e graxarias. São Paulo - CETESB, fev. 1993

CNPC - Conselho Nacional de Pecuária de corte, 2011-06-09

DIPOA - Departamento de Inspeção de Produtos de Origem Animal

FRANCO, B. D. G. M, LANDGRAF, M. Microrganismos Patogênicos de Importância em Alimentos. In: Microbiologia dos alimentos. São Paulo: Atheneu, 1996, cap. 4, p. 33-82-182 p

FRAZIER, W.C, WESTHOFF, D. C. Microbiologia de los alimentos, Zaragoza, Acribia, 1993

HOOBS, B. C, ROBERTS, D. Toxinfecções e Controle Higiênico - Sanitário de Alimentos. São Paulo: Varela . Parte I, cap.3, p.25 - 47, 1992

IBGE - Instituto Brasileiro de Geografia e Estatística ( 2007 )

JAY, J. M, Microbiologia de Alimentos. 6, ed. Porto Alegre: Artmed, 2005, 712 p. 
KARMALI. MA, STEELE BT, PETRIC M, LIM C. Sporadic cases of haemolytic, 1983

MARQUES, J. A, PRADO, I. N, MOLETTA, J. L, et al. Características físico - químicas da carcaça e da carne de novilhas submetidas ao anestro cirúrgico ou mecânico terminadas em confinamento, Revista Brasileira de Zootecnia , v.35, n.4, p. 1514 - 1522, 2006

MARTINS, S. C. S, et al. Screening de linhagens de Escherichia coli multiresistentes a antibióticos, em alimentos de origem, animal no estado do Ceará, Brasil. Higiene Alimentar, São Paulo, v.17, n.104/105, p.71, jan/fev. 2003

MAPA - Ministério da Agricultura, Pecuária e Abastecimento.

NATARRO, J. P, KAPER, J. B. Diarrheagenic Escherichia Coli. 1998

PACHECO, J. W. F, YAMANAKA, H. T. - Setor de Tecnologias de Produção mais limpa. 2008

PENSEL, N, - The future of red meat in humans diets. Nutr. Abs. Ver. (Series A), v.68, n.1, p.1-4, 1998

RIISPOA - Regulamento de Inspeção Industrial e Sanitária dos Produtos de Origem Animal ROÇA, R.O, Influência do banho de aspersão "ante-mortem" em parâmetros bioquímicos e microbianos da carne bovina. Campinas. F. E. A / Unicamp, 1993. 185 p.

ROÇA, R.O, SERRANO, A. M, Influência do banho de aspersão "ante-mortem", em parâmetros bioquímicos e na eficiência da sangria da carne bovina. Pesquisa Agropecuária Brasileira, Brasília, v.30, n.8, p.1107 -1115, 1995

ROTA, E. L, OSORIO, M. T. M, OSORIO, J. C. S, et al. Influência da castração e da idade de abate sobre as características subjetivas e instrumentais da carne de cordeiro. Revista Brasileira de Zootecnia, v.35, n.6, p.2397 - 2405, 2006

RYLEY, REMIS RS, Hemorrhagia colitis associated with a rare Escherichia coli serotype. N. Enge. J. Med. - 1983

TRABULSI, L.R Bactéria encontrada no hambúrguer, podendo ser mortal. Agência USP de notícias, São Paulo, n.389/99. abr . 1999

UFES - Universidade Federal do Espírito Santo - Boletim Técnico - PIE - UFES - 007 - Editado 01/08/2007. 